\title{
Comissões de controle de infecę̧̃o hospitalar do interior do Maranhão, Brasil
}

\author{
|Committees of hospital infection control of public hospital Maranhão, Brasil.
}

\author{
Marcelino Santos Neto' \\ Mareos Roberto de Matos Oliveira² \\ Floriacy Stabnow Santos ${ }^{3}$ \\ Francisca Jacinta Feitoza de Oliveira ${ }^{4}$ \\ Ana Cristina Pereira de Jesus Costa ${ }^{5}$ \\ Adriana Gomes Nogueira Ferreira ${ }^{6}$
}

\section{Resumo}

A Comissão de Controle de Infecção Hospitalar é uma instancia colegiada, formada por técnicos de diversas disciplinas, que tem como função criar e cumprir o Programa de Controle de Infecção Hospitalar (PCIH). Este estudo objetivou avaliar o funcionamento das $\mathrm{CCIH}$ dos hospitais públicos de um município do interior do estado do Maranhão, Brasil a partir do cumprimento das ações do $P C I H$. Trata-se de um estudo descritivo, transversal, realizado em dois hospitais públicos do município, no período de fevereiro a junho de 2011, por meio de aplicação do roteiro de inspeção do Programa de Controle de Infecção Hospitalar elaborado pela Agência Nacional de Vigilância Sanitária (ANVISA) e observação da existência do Regimento Interno de cada CCIH.O Hospital A cumpriu 100\% dos itens imprescindíveis, $91,11 \%$ dos itens necessários, $80,00 \%$ dos itens recomendados e $80,77 \%$ dos itens informativos. O Hospital B também cumpriu $100 \%$ dos itens imprescindíveis, $97,78 \%$ dos itens necessários, $90,00 \%$ dos itens recomendados, e $73,08 \%$ dos itens informativos. Conclui-se que ambas as CCIH estudadas estavam implantadas de acordo com a regulamentação nacional e que a enfermagem exerce um papel importante nestas comissões. No entanto destaca-se a necessidade de se avaliar sua eficácia em estudo posterior.

\footnotetext{
Abstraet

The Commission of Infection Control is an instance collegiate formed by technicians from various disciplines, which aims to create and fulfill the Program Infection Control $(\mathrm{PCIH})$. Evaluate the functioning of the Committees of the Hospital Infection Control in public hospitals Imperatriz-MA. This was a descriptive transversal study, conducted at two public hospitals in the period from February to June 2011, through application of the inspection checklist Control Program prepared by the Hospital Infection Surveillance Agency (ANVISA) and observation of the existence of the Bylaws of each CCIH. The Hospital A fulfilled $100 \%$ of the essential items, $91.11 \%$ of the required items, $80.00 \%$ of the recommended items and $80.77 \%$ of the informational items. Hospital B also fulfilled $100 \%$ of the essential items, $97.78 \%$ of the required items, $90.00 \%$ of the recommended items, and $73.08 \%$ of the informational items. Thus it is concluded that both $\mathrm{CCIH}$ studied were implemented in accordance with national regulations and that nursing plays an important role in these committees. However highlight the need to evaluate their effectiveness in further studies.
}

Deseritores: Avaliação. Controle. Infeçãa Hospitalar. Enfermagem.

Keywords: Evaluation. Control. Hospital Infeetion. Nursing.

\begin{abstract}
${ }^{1}$ Farmacêutico-bioquimico, especialista em Citologia Clinica, Saúde da Familia, Educaḳ̂̃o a Distâneia, Gestão em Saúde, Mestre em Gestão e Teenologia Farmacêutiea e Doutorando em Saúde Pública pela EERP/USP.

2 Agadêmieo do $5^{0}$ periodo do Curso de Medieina do Instituto Iocantinense Presidente Antônio Carlos Porto [IIPAC] Porto Nacional [TO], Brasil;
\end{abstract}

\begin{abstract}
${ }^{3}$ Enfermeira. Doutoranda em Saúde Públiea pela Eseola de Enfermagem de Rihbeirão Preto, Universidade de São Paulo, Rỉbeirão Preto [SP] Brasill. Professora Assistente III, Curso em Enfermagem, Universidade Federal do Maranhão - UFMA - Imperatriz [MA] Brasil
\end{abstract}
${ }^{4}$ Enfermeira. Mestre em Efetividade em Saúde baseada em Evidêneias pela Universidade Federal de São Paulo, Brasil. Professora Assistente II, Curso em Enfermagem, Universidade Federal do Maranhão - UFMA - Imperatriz [MA] Brasil

\footnotetext{
5 Enfermeira. Mestre em Enfermagem pela Universidade Federal do Ceará. Professora Assistente I, Curso em Enfermagem, Universidade Federal do Maranhão - UFMA - Imperatriz [MA] Brasil

${ }^{6}$ Enfermeira. Doutoranda em Enfermagem pela Universidade Federal do Ceará. Professora Assistente I, Curso em Enfermagem, Universidade Federal do Maranhão - UFMA - Imperatriz [MA] Brasil.
}

Para correspondência:

Marcelino Santos Neto

E-mail: marcelinosn@gmail.com

Data da Submissão: 20/02/2014 Data do Aceite: 20/02/2014 
Introdução

O contato com posterior permanência temporária ou permanente de organismos parasitas com o corpo humano constitui infecção, tal relação tende a ocasionar déficits funcionais ao organismo parasitado. Grande parte dos procedimentos realizados na área de saúde é voltada para o controle, tratamento ou prevenção de agravos relacionados à infecção, a qual pode ser adquirida em âmbito comunitário ou hospitalar (1).

A Portaria No 2616/98 do Ministério da Saúde do Brasil conceitua Infecção Hospitalar como aquela adquirida após admissão do paciente e que se manifesta durante a internação ou após a alta; quando puder ser relacionada à internação ou a procedimentos hospitalares; aquelas manifestadas antes de 72 horas da internação, quando associadas a procedimentos diagnósticos e/ou terapêuticos, realizados durante este período. No recém-nascido as infecções adquiridas são hospitalares, exceto as transmitidas por via transplacentária e associadas à bolsa rota superior a 24 horas (2).

Desde 2004 a Agencia Nacional de Vigilância Sanitária (ANVISA), órgão responsável por moderar as Comissões de Controle de Infecção Hospitalar (CCIH) do Brasil, considera o uso da expressão IRAS, para denominar a Infecção Relacionada à Assistência à Saúde (1). Essa denominação amplia o leque de intervenções preventivas, já que a assistência em saúde não se restringe ao ambiente hospitalar.

De acordo com a Portaria No 2.616/98 do Ministério da Saúde, a CCIH é uma comissão formada por técnicos de nível superior, que tem como função criar e cumprir o Programa de Controle de Infecção Hospitalar (PCIH), o qual é um conjunto de ações sistematizadas que visam prevenir e reduzir agravos infecciosos. Esse programa preconiza diversas intervenções tais como: implantação de um sistema interno de prevenção epidemiológica, notificação e controle estatístico de casos suspeitos e confirmados, uso racional de antibióticos e germicidas, educação continuada dos profissionais próprios da instituição, dentre outras ações ${ }^{(2)}$.

As infecções hospitalares são um problema de saúde reconhecido há muitos anos, contudo ainda geram muitos transtornos ao sistema de saúde. Em estudo, a cerca de resistência bacteriana em Unidades de Terapia Intensiva, de 65 hospitais do
Brasil verificou que a mortalidade global dos pacientes sépticos foi de $46,6 \%$ (243 pacientes). Em relação aos pacientes com choque séptico, a mortalidade encontrada foi de $65,3 \%$ e na sepse grave de $34,4 \%$ (3).

No entanto a existência da CCIH na instituição de saúde não significa garantia de proteção para os usuários e funcionários da mesma. É sabido que boa parte dos hospitais principalmente públicos apresentam carências materiais e humanas, sendo que tais influenciam no funcionamento das CCIH ${ }^{(4)}$. É necessário que a $\mathrm{CCIH}$ funcione de maneira adequada já que mesmo sendo atuante a mesma enfrenta vários problemas devido à complexidade do serviço.

Com isso esse estudo objetivou avaliar o funcionamento das $\mathrm{CCIH}$ dos hospitais públicos de um município do interior do estado do Maranhão, Brasil a partir do cumprimento das ações do PCIH.

\section{Metodologia}

Estudo descritivo, transversal, realizado em município do interior do estado do Maranhão, em dois hospitais públicos. Os dados foram coletados no mês de maio de 2011, por meio de aplicação do roteiro de inspeção do Controle de Infecção Hospitalar (RDC No 48, de 02 de junho de 2000), o roteiro de entrevistas continha questões abertas e fechadas.

Neste território existem três hospitais públicos sendo um geral, um obstétrico neonatal, e outro especializado em saúde mental. A unidade especializada em saúde mental não possui CCIH, desta forma não foi incluído no estudo.

Em respeito ao anonimato e confidencialidade os hospitais foram denominados de Hospital A e B. O Hospital A é um hospital geral, 290 leitos sendo 196 adultos e 94 pediátricos, além de seis leitos rotativos na sala de recuperação pósanestésica. A Unidade de Terapia Intensiva (UTI) da mesma instituição possui 10 leitos adultos e sete pediátricos. O Hospital B é de especialidade materno-infantil, e possui 68 leitos clínicos e 41 de UTI.

Nos Hospitais A e B o roteiro de entrevista foi aplicado junto ao enfermeiro executor da comissão, os dados coletados foram analisados de acordo com a Portaria MS 2.616/98 (2).

$\mathrm{O}$ roteiro de entrevista foi constituído por 94 perguntas, sendo 67 fechadas e 27 abertas. As questões eram subdivididas em quatro categorias, 
por consideração do risco inerente a cada item, sendo classificadas em: Imprescindível (I), aquele item que pode influir em grau crítico na qualidade e segurança do atendimento hospitalar, havendo 13 itens em tal categoria; Necessário (N), aquele item que pode influir em grau menos crítico na qualidade e segurança do atendimento hospitalar, existindo 45 itens nessa classificação; Recomendado (R), aquele item que pode influir em grau não crítico na qualidade e segurança do atendimento hospitalar, dos quais se enquadram 10 itens; Informativo (INF), aquele que oferece subsídios para melhor interpretação dos demais itens, sem afetar a qualidade e a segurança do atendimento hospitalar, por meio do requerimento de informações tais como taxas de notificação e procedimentos, sendo 26 itens inseridos nesta categoria.

Os dados foram analisados e tabulados em planilha do programa Microsoft Office Excel 2010, tendo sido feita diferenciação numérica entre os itens cumpridos e não cumpridos, informados e não informados pelas instituições estudadas segundo subdivisão exposta. Outros dados tabulados foram: número de profissionais divididos por categoria, além das cargas horárias semanais cumpridas pelos mesmos em cada comissão.

À medida que o roteiro era aplicado junto aos profissionais, documentos e rotinas tais como protocolos de atividades e métodos estatísticos de notificação eram expostos e demonstrados. Em cada unidade as visitas bem como aplicação do roteiro tiveram duração de uma semana.

O estudo obedeceu aos aspectos éticos de pesquisa em seres humanos conforme parecer $n^{\circ}$ 139/11 aprovado pelo Comitê de Ética em Pesquisa da Universidade Federal do Maranhão.

\section{Resultados}

Os resultados foram organizados em Recursos humanos nas $\mathrm{CCIH}$ e critérios técnicos relacionados ao funcionamento das $\mathrm{CCIH}$ nos referidos hospitais.

A Tabela 1 apresenta um demonstrativo dos recursos humanos disponíveis nas $\mathrm{CCIH}$ das unidades hospitalares contempladas no estudo.

\begin{tabular}{llrcc}
\hline Categoria profissional & \multicolumn{4}{c}{ Hospitais } \\
\cline { 2 - 5 } & $\mathrm{A}$ & $\mathrm{CH} / \mathrm{sem}$ & $\mathrm{B}$ & $\mathrm{CH} / \mathrm{sem}$ \\
\hline Enfermeiro & 3 & $20 \mathrm{H}$ & 1 & $30 \mathrm{H}$ \\
Médico & 2 & $20 \mathrm{H}$ & 1 & $20 \mathrm{H}$ \\
Farmacêutico & 1 & $20 \mathrm{H}$ & 0 & 0 \\
Administrador & 1 & $20 \mathrm{H}$ & 1 & $20 \mathrm{H}$ \\
Outros de nível médio & 1 & $20 \mathrm{H}$ & 1 & $30 \mathrm{H}$ \\
\hline Tabela 1 Categoria profissional, quantidade e carga horária \\
por profissional disponíveis nas CCIH dos Hospitais A e B. \\
Imperatriz-MA, 2011.
\end{tabular}

Fonte : pesquisa direta

Conforme demonstrado na Tabela 1 o Hospital A possui oito membros e o Hospital B quatro. No entanto é válido considerar o número de leitos de cada unidade. Sendo que a Unidade A possui 290 e a Unidade B 68 leitos. Ambas as comissões possuem enfermeiros e médicos e possuem representantes da administração.

De acordo com a Tabela 1, todos os profissionais da CCIH do Hospital A cumprem 20 horas semanais, já no Hospital B, o profissional enfermeiro e o técnico de enfermagem, cumprem 30 horas semanais.

A Tabela 2 apresenta numericamente $o$ resultado geral do roteiro de inspeção aplicado junto a um enfermeiro da CCIH do Hospital A.

Observou-se que $100 \%$ dos itens Imprescindíveis (I) foram cumpridos. Dos Necessários (N) 41 (91,11 \%) foram cumpridos e 4 $(8,89 \%)$ não. Dos itens Recomendados (R) 8 $(80,00 \%)$ foram cumpridos e $2(20,00 \%)$ não. Em relação aos itens Informativos (INF), 21 (80,77\%) foram informados e $5(19,23 \%)$ não, sendo que desses, 4 (15,38\%) não se aplicavam à realidade do hospital por requererem informações sobre unidades não existentes no mesmo, a saber: UTI

\begin{tabular}{lcccc}
\hline \multicolumn{1}{c}{ Itens } & $\begin{array}{c}\text { Imprescindíveis } \\
(I)\end{array}$ & $\begin{array}{c}\text { Necessários } \\
(N)\end{array}$ & $\begin{array}{c}\text { Recomendados } \\
(\boldsymbol{R})\end{array}$ & $\begin{array}{c}\text { Informativos } \\
(\text { INF })\end{array}$ \\
\hline Sim & 13 & 41 & 8 & - \\
Não & - & 4 & 2 & - \\
Informado & - & - & - & 21 \\
Não Informado & - & - & - & 5 \\
\hline
\end{tabular}

Tabela 2. Itens Cumpridos e não Cumpridos, Informados e não Informados pela CCIH do Hospital A.

Fonte: pesquisa direta 
neonatal, Berçário de alto risco e Unidade hemato-oncológica.

Dentre os itens (N) e (R) não cumpridos pelo Hospital $\mathrm{A}$, dois $(\mathrm{N})$ e um $(\mathrm{R})$ dizem respeito à utilização de antimicrobianos, onde se questiona se é realizado o controle sistemático da prescrição de antimicrobianos, se existe formulário para a prescrição de antimicrobianos, e se há orientação médica ou consulta ao infectologista da CCIH. Neste contexto o item (INF) não informado requeria $o$ percentual de antimicrobianos utilizados em cirurgia nos últimos 12 meses. Por não haver controle sistemático, esse item também não poderia ser informado.

Na tabela 3 encontram-se os resultados específicos sobre a CCIH do hospital B. Na tabela 3 verificou-se que todos os itens Imprescindíveis (I) foram cumpridos, quanto aos Necessários (N) $44(97,78 \%)$ foram cumpridos, dos Recomendados (R) $9(90,00 \%)$ foram cumpridos, quanto aos itens Informativos (INF) 19 (73,08\%) foram informados e $7(26,92 \%)$ não dos quais $5(19,23 \%)$ não se aplicam, por contemplarem serviços não existentes no hospital: UTI adulto, UTI pediátrica, Unidade de Queimados, Hemato-oncológica, Unidade de Soropositivos.

\section{Diselıssão}

As atividades de controle de infecção hospitalar deveriam ser preferencialmente coordenadas e/ou executadas por profissionais infectologistas ou farmacêuticos clínicos com formação em antimicrobianos (5). Desta forma a Comissão de Controle de Infecção Hospitalar (CCIH) deverá ser formada preferencialmente por um enfermeiro um segundo profissional de nível superior não seja necessariamente um médico ${ }^{(2)}$.

Apesar de o médico infectologista apresentar um importante papel nas comissões, o modelo brasileiro de controle de infecções sempre enfatizou o trabalho em equipe, destacando a importância da enfermagem, pelo seu maior contato com o paciente e sua atuação decorrente de seu diagnóstico e condutas especificas, coordenando na prática a execução da maioria das medidas profiláticas recomendadas ${ }^{(6)}$. Ter um médico infectologista integrando a comissão de controle é importante, pela formação profissional ser especifica aos objetos de trabalho das $\mathrm{CCIH}$, contudo os fatores experiência profissional e trabalho em equipe são imprescindíveis para o bom funcionamento de uma comissão.

Quanto aos outros profissionais destacados na CCIH do Hospital B (Tabela 1) é representado por um técnico de enfermagem. Sobre este assunto a Portaria $\mathrm{N}^{\circ}$ 2616/98 exige que sejam no mínimo dois técnicos de nível superior para cada 200 leitos ou fração, sendo que um dos executores seja preferencialmente um enfermeiro (2). Assim a referida portaria não aborda sobre a existência de um profissional de nível técnico nas comissões desde que assegure no mínimo dois técnicos de nível superior.

O enfermeiro, na maioria das vezes, é o que assume o maior número de responsabilidades no serviço de controle de infecção. Isso decorre em função da maior carga horária designada, além de exigida exclusividade para o serviço em 6 horas diárias, em relação às demais categorias profissionais. Os outros membros, pela designação da portaria, têm uma carga reduzida, favorecendo o acúmulo de outras funções na instituição ${ }^{(7)}$.

De acordo com a Portaria 2616/98 a carga horária diária mínima que o enfermeiro deverá disponibilizar será de 6 horas totalizando 30 horas semanais, sendo necessário acrescentar duas horas semanais para cada 10 leitos destinados aos pacientes de alta gravidade (terapia intensiva, berçário de alto risco, queimados, transplante de órgãos, pacientes hemato-oncológicos ou com AIDS) (2). Desta forma é evidente a necessidade de atenção diferenciada quanto à vigilância e

\begin{tabular}{ccccc}
\hline Itens & $\begin{array}{c}\text { Imprescindíveis } \\
(I)\end{array}$ & $\begin{array}{c}\text { Necessários } \\
(N)\end{array}$ & $\begin{array}{c}\text { Recomendados } \\
(\text { R) }\end{array}$ & $\begin{array}{c}\text { Informativos } \\
(\text { INF })\end{array}$ \\
\hline Sim & 13 & 44 & 9 & - \\
Não & - & 1 & 1 & - \\
Informado & - & - & - & 19 \\
Não Informado & - & - & - & 7 \\
\hline
\end{tabular}

Tabela 3. Itens Cumpridos e não Cumpridos, Informados e não Informados Pela CCIH do Hospital B, Imperatriz-MA, 2011.

Fonte: Pesquisa direta 
medidas de controle nestas unidades.

Conforme apresentado na Tabela 1, três enfermeiros do PCIH do Hospital A cumprem 20 horas semanais para 296 leitos gerais e 17 leitos de UTI. Sobre a carga horária individual está encontra-se abaixo da determinada pela portaria $2.616 / 98^{(2)}$, contudo o número de profissionais é adequado.

Quanto às competências da Comissão é destacada a necessidade de se instituir, medidas para o uso racional de antimicrobiano em cooperação com o serviço de Farmácia e Terapêutica (2). É sabido que para contribuir com a redução da disseminação da resistência microbiana em serviços de saúde, faz-se necessário dentre outras ações, capacitar prescritores para o uso racional de antimicrobianos ${ }^{(8)}$.

A ANVISA recomenda algumas ações para a redução da resistência bacteriana, a saber, adicionar conteúdo sobre uso racional de antimicrobianos em disciplinas do ensino médio; incluir na estrutura do Programa de Saúde da Família e de outros programas de promoção a estratégias de uso racional de antimicrobianos; desenvolver campanhas sobre uso racional de antimicrobianos através dos meios de comunicação; habilitar profissionais da $\mathrm{CCIH}$ para o uso racional de antimicrobianos; capacitar os profissionais de $\mathrm{CCIH}$ para antibioticoprofilaxia e desenvolver e implementar sistema de informação com módulo de avaliação do consumo e controle de antimicrobianos( ${ }^{(9)}$.

Sobre os coeficientes de sensibilidade/resistência dos microrganismos aos antimicrobianos, e a emissão de relatórios de sensibilidade/resistência bacteriana para o corpo clínico e CCIH a pesar de serem Recomendados (R) e Necessário (N) não foram cumpridos pelo Hospital A.

Em estudo intitulado avaliação da prescrição de antimicrobianos de uso restrito em um hospital, verificou indicadores de uma CCIH que possui rotina normalizada bem como formulário e protocolos para o uso de antimicrobianos, observou-se que $71,9 \%$ das prescrições estavam de acordo com o protocolo da $\mathrm{CCIH}$, que os médicos costumavam seguir as recomendações descritas pela Comissão, por conseguinte a taxa de infecção no ano do estudo para o hospital em questão foi de $3,8 \%$, aproximadamente quatro vezes menor que a média nacional no período que era de $15 \%(10)$.
A resistência microbiana tem aumentado nos hospitais, devido ao uso indiscriminado de antimicrobianos. $\mathrm{O}$ conhecimento da sensibilidade ou não de determinado microrganismo a um antimicrobiano, é importante para a adequada terapêutica. Este indicador fornecerá o perfil de resistência microbiana dentro da Instituição (2).

Em estudo sobre resistência bacteriana, argumentam que o aumento dos dias de internação e os consequentes custos com terapêutica antimicrobiana além das questões individuais relacionados à perda de salários e alterações psicológicas dos pacientes, por si só evidenciariam a importância da prevenção de controle de infecção hospitalar (IH). As características multifatoriais que lhe são peculiares demandam medidas diversas, sendo que uma das mais importantes é o controle do uso dos antibióticos e consequentemente o controle da resistência bacteriana por meio de determinação e acompanhamento da mesma (11).

Em pesquisa por levantamento de dados em 26 estados brasileiros e Distrito Federal observou hospitais que não contavam com laboratórios de microbiologia, estes nos estados da Região Nordeste $(46,29 \%)$ e Norte $(45,45 \%)$. Por conseguinte a determinação da resistência bacteriana era dificultada devida acesso ao serviço laboratorial (12).

O Laboratório de Microbiologia configura importante apoio estratégico às atividades $\mathrm{CCIH}$, pois o microbiologista gerencia as etapas do teste de amostra clínica, permitindo a divulgação da informação sobre as resistências bacterianas (13) deste modo é possível atuar no controle da infecção a partir da padronização das rotinas, com aplicação de métodos e parâmetros eficazes.

Os itens relacionados ao uso de antimicrobianos e controle de resistência, não são classificados como Imprescindível (I) pelo roteiro de inspeção, contudo estão intimamente ligados as complicações vitais para os pacientes, sendo o descontrole dessas ações aspecto importante para o surgimento de novas infecções.

Outros itens Necessário (N) e Recomendados (R) respondidos negativamente pelo Hospital A, trata-se dos mecanismos para detecção de casos de infecção pós-alta e meios de comunicação ou integração com outros serviços de saúde para detecção de casos de infecção hospitalar.

Em pesquisa sobre vigilância pós-alta de infecção do sítio cirúrgico, verificou em uma 
amostra de 357 pacientes submetidos à cirurgia do aparelho digestivo, houve 64 casos de infecção do sítio cirúrgico notificadas, $25 \%$ diagnosticados durante a internação e $75 \%$ após a alta hospitalar. Desta forma, com a realização da vigilância pósalta, verificou-se uma taxa global de $18,0 \%$ de infecção do sítio cirúrgico, apresentando importante aumento da taxa de infecção do sítio cirúrgico, em quatro vezes quando a vigilância pós-alta foi realizada ${ }^{(14)}$.

Corroborando autores encontraram resultados diferentes em outro estudo, onde foram diagnosticadas 87 infecções de sítios cirúrgicos sendo 55 identificadas durante a internação e 32 após a alta hospitalar. Contudo o número de infecção pós-alta foi significativo ${ }^{(15)}$.

A relação paciente profissional não deveria se limitar ao ambiente, principalmente considerando o tema infecção, uma vez que a mesma não respeita território ou barreiras. Para que a assistência em saúde se torne mais eficaz, faz-se necessário fortalecer a comunicação entre hospitais e unidades básicas de saúde os quais são responsáveis pelos pacientes em seu território.

$\mathrm{O}$ item Necessário $(\mathrm{N})$ não cumprido trata da ausência de sistema de barreiras na lavanderia. A ANVISA afirma que os principais condicionantes do projeto físico da unidade de processamento são: barreira física, massa ou peso da roupa, equipamentos, instalações prediais, fluxo da roupa, técnica de processamento e jornada de trabalho ${ }^{(16) .}$

$\mathrm{Na}$ cadeia epidemiológica das infecções hospitalares a vestimenta deve ser considerada, pois os diferentes tipos de tecidos também podem influenciar na adesão e preservação da viabilidade bacteriana, reforçando a necessidade de vigilância e controle de qualidade nos processos de lavagem e desinfecção de tecidos ${ }^{(17)}$.

Autores referem que o cuidado com fluxo de limpeza é determinante associado à necessidade de implantação de barreiras físicas e outros tipos de procedimento, pois é através do fluxo adequado que se obterá o controle dos processos, combatendo o risco de infecção hospitalar (9). Deste modo é fundamental a existência de barreiras físicas na unidade de processamento de roupas, no entanto nem sempre os hospitais estão estruturalmente adequados.

$\mathrm{O}$ item Recomendado (R) respondido negativamente aborda sobre a existência de consórcio com outros hospitais para utilização recíproca de recursos técnicos, materiais e humanos na implantação do PCIH. A necessidade de apoio extra institucional é identificada pela CCIH e administração, que não sendo necessário, não há necessidade de firmar parceria.

Em relação aos itens Informativos (INF) que se aplicam ao hospital B, dois não foram informados. Esses itens solicitam a taxa de infecção hospitalar dos últimos 12 meses, e o número de ocorrência de acidentes com pérfuro-cortantes com funcionários dos últimos seis meses.

Outro aspecto importante a ser considerado é o fato de que existem esforços das autoridades públicas visando a regulamentação das atividades de controle, a divulgação das informações, como também de associações de profissionais de saúde e outras entidades privadas que tem contribuído na formação, atualização e motivação do pessoal da área ${ }^{(18)}$.

\section{Conelusão}

Ambos os hospitais possuem $\mathrm{CCIH}$ implantadas e atendendo aos requisitos de acordo com as recomendações da ANVISA no que consiste a recursos humanos e horas disponibilizadas.

Sobre os critérios técnicos contemplados foi possível observar que os itens imprescindíveis foram atendidos em ambos os hospitais. No tocante aos demais itens o hospital A atendeu a $91,11 \%$ dos necessários, $80,00 \%$ dos recomendados e informou $80,77 \%$ dos itens informativos. Os itens não realizados dizem respeito à realização do controle sistemático da prescrição de antimicrobianos, orientação médica ou consulta ao infectologista da $\mathrm{CCIH}$, ausência de protocolos para prescrição de antimicrobianos e de levantamento da sensibilidade/resistência dos microrganismos aos antimicrobianos, existência de mecanismos para deteç̧ão de casos de infecção pós-alta. Dentre os itens não informados o de maior relevância requeria o percentual de antimicrobianos utilizados em cirurgia nos últimos doze meses. Quanto ao Hospital B os itens necessários foram atendidos em 97,78\%, recomendados $90,00 \%$ e itens informativos $73,08 \%$. Entre os não realizados destaca-se a inexistência de método de barreira na lavanderia. Em relação aos critérios Informativos não informados destacam-se, a taxa de infecção hospitalar dos últimos 12 meses, e o número de ocorrência de acidente com pérfuro-cortantes com funcionários dos últimos seis meses. 
Desta forma conclui-se que ambas as $\mathrm{CCIH}$ estudadas estavam implantadas de acordo com a regulamentação nacional e que a enfermagem exerce um papel importante nestas comissões. No entanto destaca-se a necessidade de se avaliar sua eficácia em estudo posterior, haja vista não ser este o objetivo deste artigo.

\section{Referências}

1. Brasil. Ministério da Saúde. Doenças infecciosas e parasitárias: guia de bolso. Brasília, 2004. 4. ed. ampl. Brasília: 2004. Disponível em: http:/ / bvsms.saude.gov.br/bvs/publicacoes/guia_bolso _4ed.pdf. Acesso em 17 mai 2010.

2. Brasil. Ministério da Saúde. Portaria No 2.616, de 12 de maio de 1998. Expede na forma de anexos diretrizes e normas para a prevenção e controle das infecções hospitalares. Diário Oficial da União 1998 jul.

3. Sales JAL, David CM, Hatum R, et al. Sepse Brasil: Estudo Epidemiológico da Sepse em Unidades de Terapia Intensiva Brasileiras. Rev Bras Ter Intensiva 2006; 18(1):917.

4. Oliveira R, Maruyama SAT. Controle de infecção hospitalar: histórico e papel do estado. Rev Eletr Enf [Internet] 2008;10(3):775-83. Disponível em: http://www.fen.ufg.br/revista/v10/n3/v10n3a23.htm. Acesso em 10 jun 2010.

5. Silva RSB, Fonseca JFA. Manual de Medidas de Prevenção das Principais Infecções Hospitalares. Brasil, $2006 . \quad$ Disponível em: http:/ /143.107.64.15/arquivos/Manual_CCIH_2009.pdf Acesso em 16 jun 2010.

6. Fernandes AT, Schaiber LB. O que pode acontecer com as Infecções Hospitalares no Brasil? Prat Hosp 2008; 10(60):10-5.

7. Barbosa MEM, Siqueira DC. A educação e a atuação do enfermeiro no controle de infecção hospitalar no estado do Paraná. Voos Revista Polidisciplinar Eletrônica da Faculdade Guairacá 2009;1(1):3-17.

8. Weber IC, Noal CB, Winckler Neto CHDP, Santos RCV. Prevalência e perfil de resistência de microorganismos isolados de uma unidade de tratamento intensivo de um hospital da região central do Rio Grande do Sul. Prat Hosp 2009; 66: 57-62. Disponível em: http:/ / www.praticahospitalar.com.br/pratica \%2066/pdf /14.pdf Acesso em: 27 maio. 2011.

9. Brasil. Agência Nacional de Vigilância Sanitária. Processamento de roupas em serviços de saúde: prevenção e controle de riscos Brasília: ANVISA, 2009. Disponível

em: http://www.anvisa.gov.br/servicosaude/manuais/proc essamento_roupas.pdf Acesso em: 17 set 2013.

10. Diefenthaeler HS. Avaliação da prescrição de uso restrito em um Hospital Universitário de Passo Fundo/RS [Dissertação de mestrado] Programa de Pós-Graduação em Ciências Farmacêuticas, Universidade Federal do Rio Grande do Sul, Porto Alegre, 2007.

11. Fontana RT, Lautert L. A prevenção e o controle de infecções: um estudo de caso com enfermeiras. Rev Bras Enferm 2006; 59(3):257-61.

12. Santos AAM. Diagnóstico do Controle da Infecção Hospitalar no Brasil (Dissertação). Belo Horizonte (MG): Ciências da Saúde: Infectologia e Medicina Tropical.
Faculdade de Medicina da Universidade Federal de Minas Gerais; 2006.

13. Andreazzi DB, Rossi F, Wen CL. Interactive TeleEducation Applied to a Distant Clinical Microbiology Specialization University Course. Telemedicine and eHealth 2011; 17(7): 524-29.

14. Oliveira AC, Ciosak SI. Infecção de sítio cirúrgico em hospital universitário: vigilância pós-alta e fatores de risco. Rev Esc Enferm USP 2007; 41(2): 258-63.

15. Martins MA, França E, Matos JC, et al. Vigilância pós-alta das infecções de sítio cirúrgico em crianças e adolescentes em um hospital universitário de Belo Horizonte, Minas Gerais, Brasil. Cad Saúde Pública 2008; 24(5): 1033-41.

16. Rossi D, Devienne KF, Raddi MSG. Influência de fluídos biológicos na sobrevivência de Staphylococcus aureus sobre diferentes superfícies secas. Rev Ciênc Farm Básica Apl. 2008; 29(2): 211-14.

17. Elizalde EP, Gomes LS. A Importância de Projetos Arquitetônicos no Planejamento do Ambiente Hospitalar. Contribuciones a las Ciencias Sociales 2009; 5(3): apr 5.

18. Puccini PT. Perspectivas do controle da infecção hospitalar e as novas forças sociais em defesa da saúde. Ciênc. saúde coletiva [online]. 2011; 16(7): 3043-49. Disponível em: http://www.scielo.br/pdf/csc/v16n7/04.pdf. Acesso em 17 de set de 2013 . 